\title{
LA SERIE DE ÁNGELES DEL MONASTERIO DE SAN JOSÉ Y SAN ROQUE DE AGUILAR DE LA FRONTERA (CÓRDOBA).
}

\author{
MARIO ÁVILA VIVAR \\ Centro de Conservación y Restauración de Castilla-La Mancha.
}

\begin{abstract}
Resumen
En Aguilar de la Frontera (Córdoba) existen numerosas representaciones angélicas, que evidencian la gran devoción que se profesó a los ángeles en esa localidad cordobesa durante la Edad Moderna. Este artículo, basado en una Tesis Doctoral, analiza la serie del monasterio de San José y San Roque, sus relaciones con otras series españolas y americanas, y reformula la nomenclatura de los ángeles y el significado de la serie.
\end{abstract}

Palabras clave.

Angelología del Barroco. Series angélicas. Ángeles apócrifos. Alegoría.

\section{THE SERIES OF ANGLES OF THE MONASTERY OF SAINT JOSEPH AND SAINT ROCH OF AGUILAR DE LA FRONTERA (CÓRDOBA).}

\begin{abstract}
In Aguilar de la Frontera (Córdoba) there exists numerous angelic representations, that evidence the great devotion that they professed to the angles in this town in Córdoba during the Modern Age. The article, based on a Doctoral Thesis, analyzes the series of the monastery of Saint Joseph and Saint Roch, their relation with other Spanish and American series, and reformulates the nomenclature of the angles and the significance of the series.
\end{abstract}

Key words.

Angelology in Baroque. Angelic Series. Apocryphal Angels. Allegory. territory from pre-roman times until Renaissance, preliminar studies make clear the historical processes into the architectural types.

Las series angélicas, como los retablos o los pasos procesionales, constituyen una seña de identidad, y una de las peculiaridades más significativas del barroco hispanoamericano. Aunque desde época bizantina se habían realizado representaciones de ángeles que podrían considerarse series angélicas, estas nunca alcanzaron tanta importancia como en el Barroco. Las series angélicas barrocas se iniciaron en España a principios del siglo XVII, alcanzaron su clímax en Andalucía, y se propagaron por todos los territorios españoles, incluidos los virreinatos americanos, donde pervivieron hasta finales del siglo XVIII. Su marco de referencia son los conjuntos seriados típicos del Barroco, como 


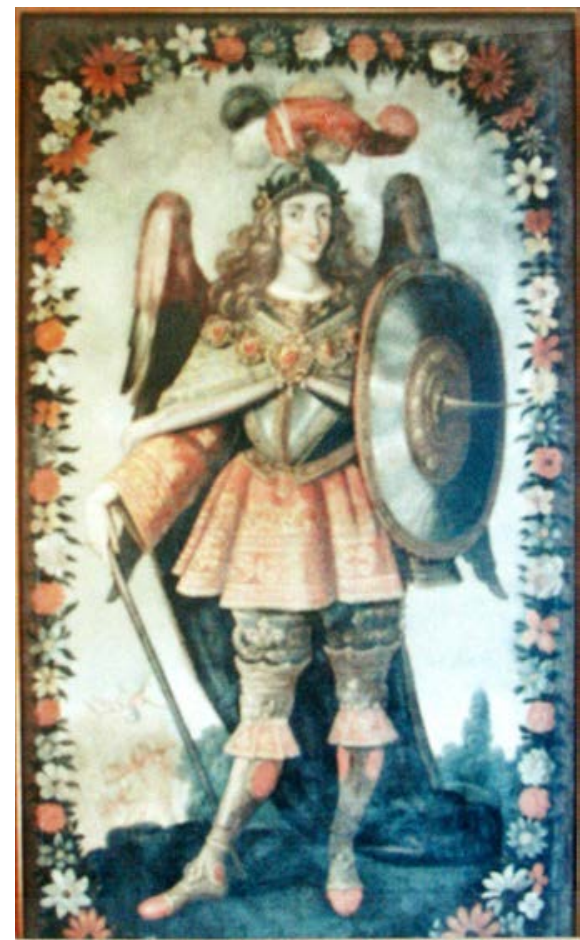

Fig.1. Miguel. Monasterio de San José y San Roque de Aguilar de la Frontera (Córdoba). Siglo XVII.

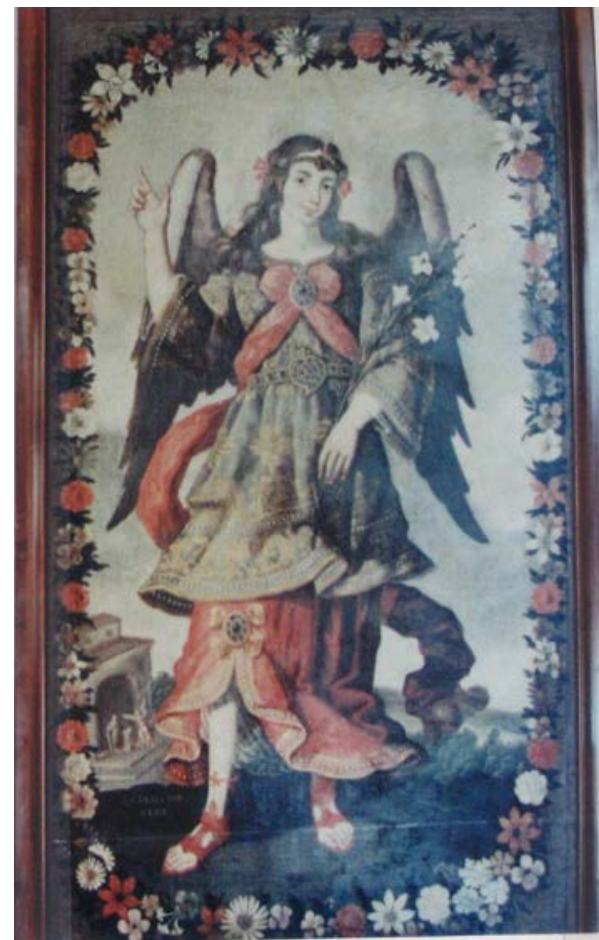

Fig. 2. Gabriel bir Deus. Monasterio de San José y San Roque de Aguilar de la Frontera (Córdoba). Siglo XVII.

las vidas de santos, los fundadores de órdenes, los personajes ilustres, etc. A pesar de ello, apenas han despertado el interés de los historiadores del arte, quienes, salvo honrosas excepciones, sólo han abordado estudios puntuales y genéricos de series concretas. En algunas series es evidente su significado, como en el caso de las de ángeles inmaculistas o pasionarios, que ostentan como atributos metáforas marianas y las arma Christi. Sin embargo, en otras, como en las de ángeles apócrifos o las de ángeles "arcabuceros" andinos, aún no se ha encontrado una respuesta satisfactoria. En las series cada ángel tiene un significado, pero el conjunto de la serie también.

Hasta donde sabemos, las series angélicas las inició un pintor cordobés llamado Bartolomé Román o Romano (Montoro, Córdoba, 1587? - Madrid, 1659), formado en el taller de Vicente Carducho y profesor de Carreño. Suyas son dos series de los Siete Príncipes de los Ángeles que se conservan en los monasterios de la Encarnación y las Descalzas Reales de Madrid, y una réplica de esta última en la iglesia de los jesuitas de Lima (Perú). A él atribuyó Tormo ${ }^{1}$ los cuadros de San Miguel, San Gabriel, y San Rafael con Tobías ${ }^{2}$, que conserva el Museo Provincial de Guadalajara, seguramente restos de alguna serie. Posiblemente también sean restos de otras series suyas el Barachiel y el Sealtiel del Museo de Palma de Mallorca, cedidos en depósito por el Museo del Prado ${ }^{3}$, y atribuidos anteriormente a Escalante por Lafuente Ferrari ${ }^{4}$; el Jehudiel y el Barachiel que había en el monasterio de Santa Isabel de Madrid, desaparecidos probablemente en $1936^{5}$, y un Sealtiel en la Colección

\footnotetext{
Tormo, 1915-1917, 10.

${ }^{2}$ Miguel y Gabriel fueron restaurados personalmente por el autor de este artículo para la exposición Celosías. Arte y Piedad en los conventos de Castilla-La Mancha durante el Siglo del Quijote (1530-1650), Museo de Santa Cruz. Toledo. 2006.

${ }^{3}$ Angulo/Pérez Sánchez, 1983, 322.

${ }^{4}$ Delgado, 2001, 316.

${ }^{5}$ Angulo/ Pérez Sánchez, 1983,322.
} 


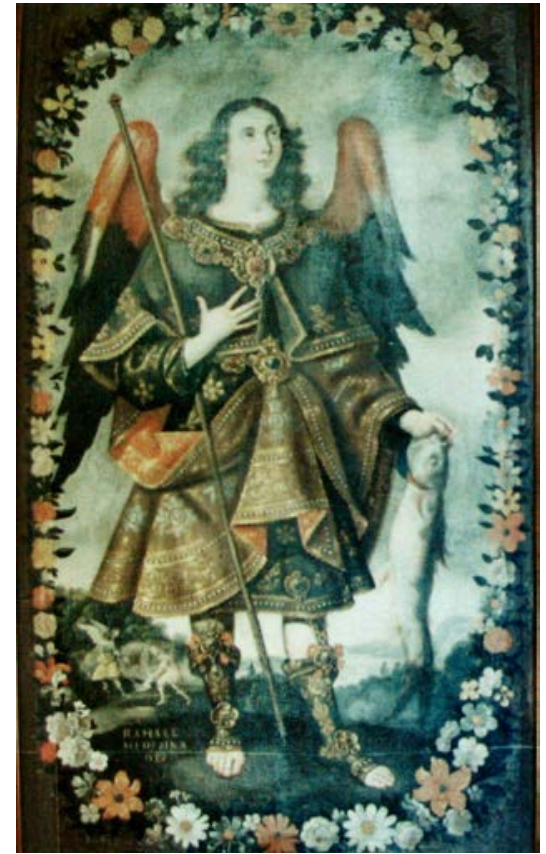

Fig. 3. Raphael Medisina Dei. Monasterio de San José y San Roque de Aguilar de la Frontera.

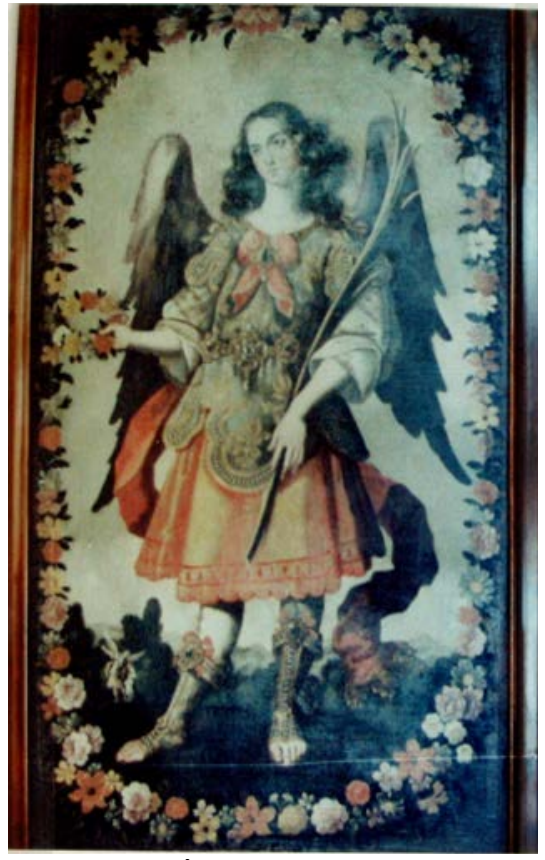

Fig. 4. Ángel de la Guarda. Monasterio de San José y San Roque de Aguilar de la Frontera.

Stoup de Murcia ${ }^{6}$. También se le atribuye el cuadro del Ángel Protector de la Comunidad del monasterio de la Encarnación, en el que figuran cuatro medallones en las esquinas que representan escenas de la vida de Mariana de San José. Según Angulo y Pérez-Sánchez ${ }^{7}$ sus ángeles siguen modelos de los grabadores flamencos del siglo XVI, en particular de Wierix y de Crispin de Passe, pero incorporando el colorido y la elegancia de la pintura italiana y la factura suelta de las pinceladas velazqueñas.

En el trascurso de la investigación que realicé para mi Tesis Doctoral ${ }^{8}$, localizamos unas cincuenta series, más de la mitad de ellas en Andalucía ${ }^{9}$, donde se encuentran las más relevantes de España, como las de la colección Aladro-Domecq, catedral de Jaén, Hospital del Pozo Santo (Sevilla), monasterio de Santa Clara de Carmona (Sevilla), San Jerónimo de Granada, o Santo Ángel Custodio de Loja (Granada). De las series existentes en la provincia de Córdoba, la más importante y conocida es la del monasterio de carmelitas descalzas de San José y San Roque de Aguilar de la Frontera, fundado en 1671 por el Alguacil Mayor del Santo Oficio, don Rodrigo de Varo y Antequera. Es una serie de once ángeles que miden unos $212 \times 115 \mathrm{~cm}$., representados sobre un paisaje crepuscular donde se insertan pequeñas escenas

bíblicas, y orlados con una guirnalda de flores de influencia flamenca. Según la tradición del monasterio, fue donada por D. Pedro de Toro y Sotomayor, obispo de Oviedo, que tenía los cuadros en su casa solariega de Aguilar, cuando su hermana, $D^{a}$ María de Vega profesó como religiosa el 3 de enero de 1673. Los ángeles llevan lujosas vestimentas sacerdotales, dalmáticas y cueras de ricos brocados, túnicas de colores, coturnos, florones, lazos volantes y cabujones. Miguel se representa con la escena de la batalla en el cielo contra el dragón, y lleva como atributo la rodela y el bastón de mando; iconografía que según mis averiguaciones fue creada por los pintores andaluces, como

\footnotetext{
${ }^{6}$ Angulo/ Pérez Sánchez,, 1983, lám. 322.

${ }^{7}$ Angulo/ Pérez Sánchez, 1983, 313-335.

${ }^{8}$ Ávila Vivar, 2013.

${ }^{9}$ Este estudio no hubiera sido posible sin la excelente colaboración del IPHA, que nos facilitó numerosos datos de la Base de Datos de Bienes Muebles de Andalucía.
} 


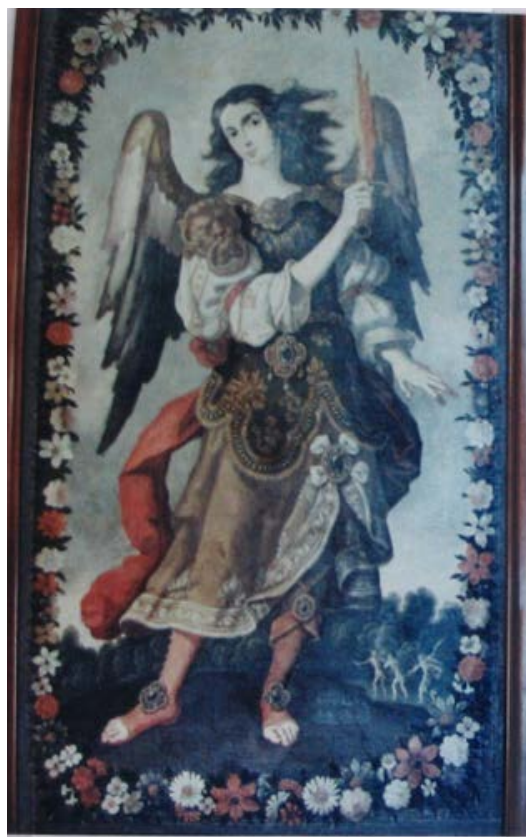

Fig. 5. Ángel del Paraíso. Monasterio de San José y San Roque de Aguilar de la Frontera (Córdoba). Escuela andaluza. Siglo XVII.

argumento en un artículo que publicará próximamente la revista Atrio, de la Universidad Pablo de Olavide (Sevilla). Gabriel bir Deus va acmpañado de la Anunciación, y tiene como atributo la vara de azucenas. Y Rafael Medisina Dei porta el bordón, la esclavina y el pez, y se compaña de la escena de Tobías sacando el pez del agua. En el resto de los cuadros no figuran inscripciones, aunque es fácil identificar al Ángel de la Guarda en el que se acompaña de un ángel que señala el cielo a un niño, y lleva como atributos una corona de flores y una palma en las manos. Un ángel tiene pintada la expulsión de Adán y Eva del Paraíso, y tiene como atributo la espada flamígera. Otro, la escena del Sacrificio de Isaac, y porta un haz de llamas en la mano. Otro, la de David ante el ángel que castigaba a Israel con la peste por su pecado, y su atributo es una espada envainada rematada con el fiel de una balanza. Otro se representa con la lucha de Jacob con el ángel, y su atributo es un ramo de espigas de trigo. Otro con la escena de Daniel en el foso de los leones ayudado por Habacuc, y porta como atributo una llave. Otro con el anuncio de la Navidad a los pastores, y lleva una rama de olivo en la mano y numerosos ojos adornando la túnica. Y otro con la escena de la liberación de San Pedro, que sostiene una columna partida, con una cadena en su fuste.

La serie fue publicada por Lara Arrebola ${ }^{10}$ en 1980, quien se propuso «aclarar problemas de atribución, onomástica angélica e iconografía», que en su opinión no estaban resueltos adecuadamente. La autoría de las pinturas la atribuyó a discípulos de Zurbarán, concretamente a Bernabé de Ayala (1625? - Cádiz, post.1689), por entender que son de estilo similar a los lienzos del Maestro de las Sibilas, que algunos historiadores identificaron con Ayala. Lara realizó un acertado estudio histórico e iconográfico, en el que describe con todo lujo de detalle los ropajes de los ángeles ${ }^{11}, 10$ pero los títulos que dio a los cuadros y sus conclusiones sobre el significado de la serie, deben ser formulados de nuevo. Siguiendo los patrones de la época, vio en los cuadros representaciones de los coros angélicos, que protagonizan las escenas representadas en la base de los cuadros. Basándose en Rèau y en los Mesa-Gisbert, denominó Raziel al ángel donde figura la escena de la expulsión del Paraíso, Peliel al que acompaña la lucha de Jacob y el ángel, Sealtiel al que figura junto al sacrificio de Isaac, y Virtud al ángel que tiene como atributo la columna partida. $Y$ basándose en sus propios criterios, intituló Ángel Exterminador al que acompaña la escena de David y el ángel que llevó la peste a Jerusalén; Querubín al que viste una Dalmática adornada con ojos,

\footnotetext{
${ }^{10}$ Lara Arrebola, 1980, 195-211.

${ }^{11}$ Lara Arrebola es un experto en tejidos, como muestra en sus libros Los tapices del patrimonio eclesiástico de Córdoba, Córdoba: Publicaciones del Monte de Piedad y Caja de Ahorros de Córdoba, 1979. Y Artes textiles en el Palacio de la Casa de Viana de Córdoba. Córdoba: Caja Provincial de Ahorros de Córdoba, 1982.
} 


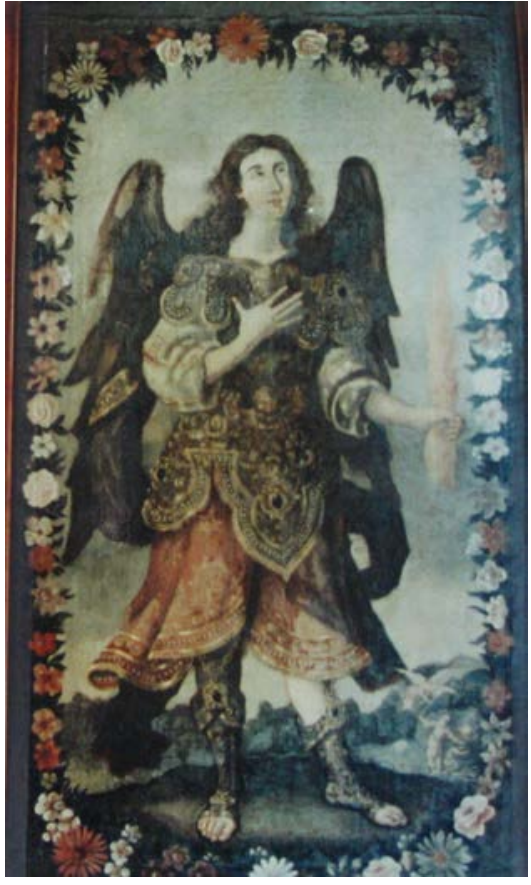

Fig. 6. Ángel de Isaac. Monasterio de San José y San Roque de Aguilar de la Frontera (Córdoba). Escuela andaluza. Siglo XVII.

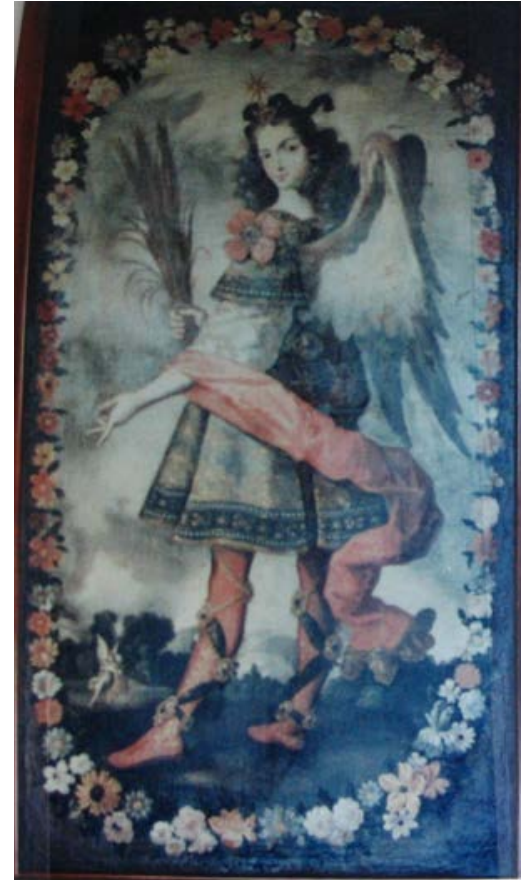

Fig. 7. Ángel de Jacob. Monasterio de San José y San Roque de Aguilar de la Frontera (Córdoba). Escuela andaluza. Siglo XVII.

puesto que así son descritos los querubines en el Libro de Ezequiel; y Ángel apocalíptico al que porta una llave en la mano derecha, por entender que este atributo lo identifica con el Quinto ángel del Apocalipsis. Así mismo, llegó a la conclusión de que la serie fue encargada para exaltar la fraternidad entre las monjas, y hacerlas sentir que formaban parte de la Comunión de los Santos. El primer significado lo dedujo de un discurso que pronunció en 1556 el prelado cordobés, don Leopoldo de Austria, exhortando al cabildo catedralicio, enfrentado por cuestiones de protocolo, a respetar cada uno la jurisdicción de su beneficio, ya que en su opinión la Iglesia Militante se había hecho a imitación de la Triunfante, donde los coros angélicos respetaban gustosamente su jerarquía. Y el segundo significado lo fundamentaba en algunas citas bíblicas relativas a la exaltación de la fraternidad entre los cristianos.

La necesidad de intitular cada uno de los ángeles que conforman una serie, ha dado lugar a propuestas arbitrarias, muchas veces basadas en criterios subjetivos. Y esto ha sido así porque al no existir un corpus que permita establecer unas normas y ponga orden en este asunto, cada historiador se ha sentido con libertad para aplicar sus propios criterios. Incluso se ha dado el caso de cambiar por otros los títulos de algunos ángeles, que los autores de los cuadros ya habían identificado con inscripciones, como hicieron algunos historiadores al analizar las series del Hospital del Pozo Santo ${ }^{12}$, o la del monasterio de la Concepción de Lima ${ }^{13}$. También son n3merosos los ejemplos de ángeles intitulados con distintos nombres, a pesar de ostentar los mismos atributos. Así, ángeles cuyo atributo es un haz de espigas se han denominado Peliel en la serie de Aguilar, Ariel lumen Dei en una colección privada de Lima, y Virtud en Calamarca (Bolivia). El ángel que envaina la espada ostenta las inscripciones de Hadriel Hablatio Dei en la serie de Pozo Santo, Esriel Justitia Dei en la de Sopó (Colombia), y Hadriel en la Concepción de Lima; y a pesar de ello se intitulo Ángel Exterminador en

\footnotetext{
${ }^{12}$ Fernández Lopez, 1991, 205-211.

${ }^{13}$ Valdivieso, 1992, 35-45.
} 


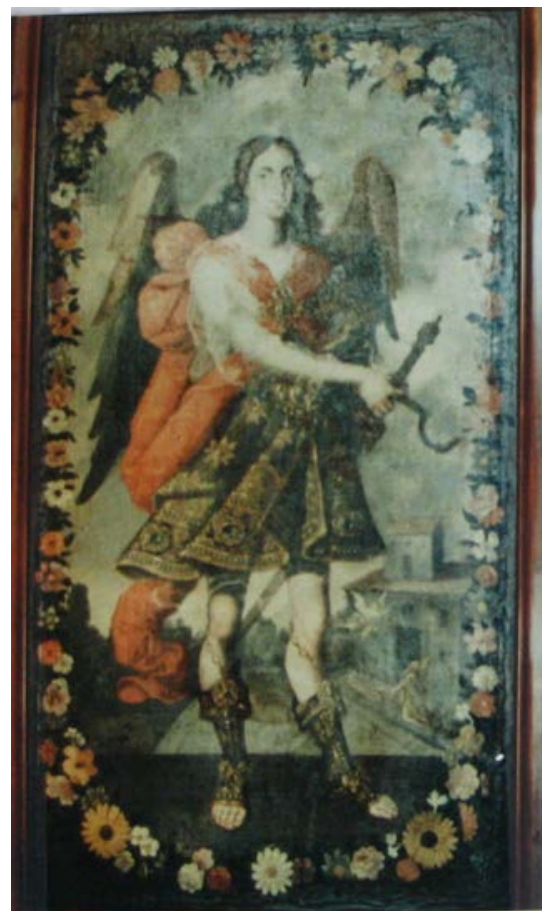

Fig. 8. Ángel de David. Monasterio de San José y San Roque de Aguilar de la Frontera (Córdoba). Escuela andaluza. Siglo XVII.

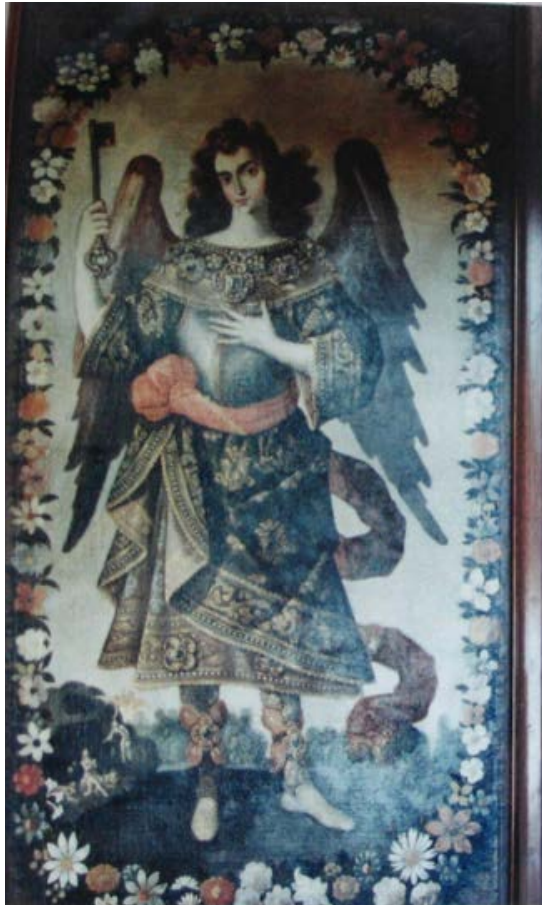

Fig. 9. Angel de Daniel. Monasterio de San José y San Roque de Aguilar de la Frontera (Córdoba). Escuela andaluza. Siglo XVII.

la serie de Aguilar, y Zadquiel «ángel de la Muerte» en la de Calamarca. Un ángel con la flama en la mano es identificado como Iaciel Aspercio Dei en la serie de Pozo Santo, y como Zadquiel en la de la Concepción de Lima. Y del mismo modo, se dieron los mismos nombres a ángeles que ostentan diferentes atributos. Como Esriel Auxilium Dei, representado con una palma y una corona de rosas en Pozo Santo, y cargando un arcabuz en la una colección limeña; o Hadriel, que envaina la espada en la Concepción de Lima, y lleva un arcabuz en una colección particular de Bolivia.

Por nuestra parte entendemos que siempre que existan, se deben respetar las inscripciones que figuran en los cuadros, e intitular con ellas a los ángeles. Y como no se ha establecido aún ninguna normativa para la nomenclatura angélica, cuando los ángeles no estén identificados con inscripciones, salvo en el caso de los ángeles canónicos y de los Siete Príncipes, no se les debe asignar nombres propios ni identidades concretas, sino intitularlos por los atributos o por las escenas que les acompañan. Por todos estos motivos, los ángeles que figuran en la serie de Aguilar no deben considerarse representaciones de los coros angélicos, que por otra parte no hemos visto nunca formando parte de las series barrocas. La asociación de las series con los coros angélicos, fue iniciada por los Mesa-Gisbert en la denominada «serie de las Jerarquías» de Calamarca (Bolivia); una conocida serie de rollizos ángeles que no tienen inscripciones que los identifiquen. Y adscribieron al coro de los Serafines al que sostiene la flama; al de las Virtudes, a los a los que sostienen la columna, portan flores, o sostienen un haz de espigas; y a los Dominios, al que porta la corona y el cetro. En nuestra opinión esta serie no representa las jerarquías celestiales del Pseudo Dionisio, sino en todo caso a los Siete Príncipes de los Ángeles, y a otros ángeles apócrifos. Así, el ángel con espada flamígera bien podría ser Uriel; el ángel con rosas en las manos, Barachiel; el ángel con cetro y corona, Jehudiel; y el ángel con flama en la mano, Seactiel, habitualmente representado con un incensario. Pero en cualquier caso, como los ángeles de Aguilar carecen de inscripciones que les identifiquen, tanto sus nombres como los títulos de los cuadros deben basarse en sus atributos y en las escenas que les acompañan. 


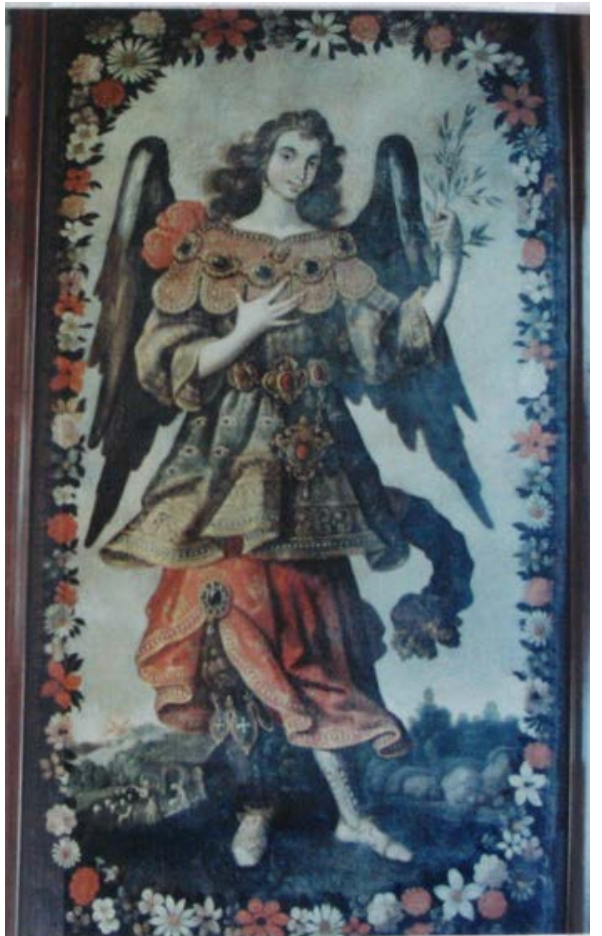

Fig. 10. Ángel de la Navidad. Monasterio de San José y San Roque de Aguilar de la Frontera (Córdoba). Escuela andaluza. Siglo XVII.

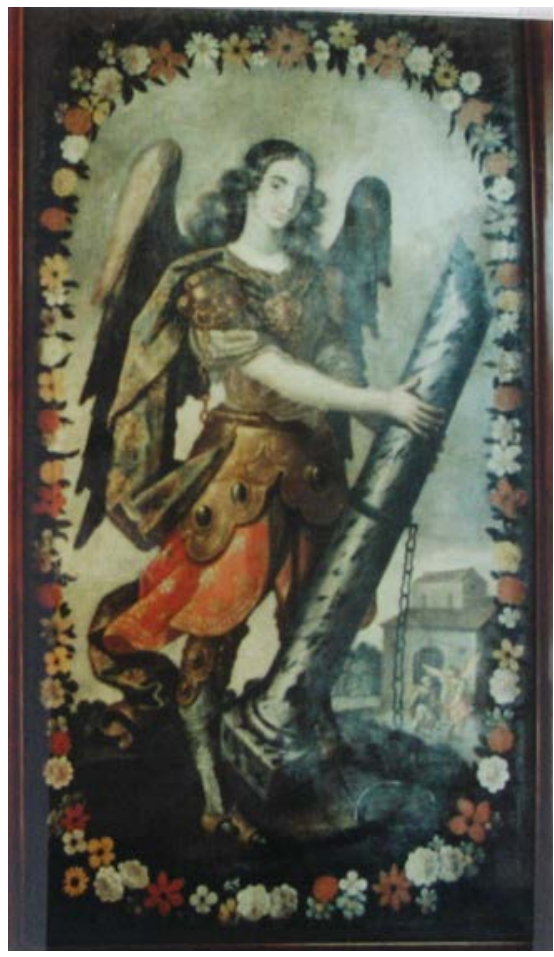

Fig. 11. Ángel de San Pedro. Monasterio de San José y San Roque de Aguilar de la Frontera (Córdoba). Escuela andaluza. Siglo XVII.

La representación de escenas junto a los ángeles fue promocionada por los grabadores flamencos, quienes editaron láminas de ángeles individuales acompañados de pequeñas escenas que protagonizan esos ángeles. Muy utilizada por los artistas españoles fue la serie de los coros angélicos grabada por Crispin van de Passe (1564-1637) hacia 1585, donde representó nueve ángeles individuales junto a escenas del Antiguo y del Nuevo Testamento. Uriel, como un Serafín junto a una escena donde instruye a Esdras; Iophiel, como un Querubín con la escena de la expulsión de Adán y Eva del Paraíso; Zaphkiel, como un Trono que observa cómo se ahoga el ejército del faraón en el mar Rojo; Raphael, como una Potestad acompañado de un pasaje del Libro de Tobías; Zadkiel, como una Dominación con la escena del sacrificio de Isaac; Haniel como una Virtud junto a una escena que muestra a los hijos de Noé mofándose de su desnudez; Camael, como un Principado con la escena de la lucha de Jacob y el ángel; Michael, como un Arcángel con una escena que le muestra peleando en el cielo con el dragón; y Gabriel, como un ángel con la escena de la Anunciación. También fue muy popular otra serie de nueve arcángeles grabada por Gerar de Jode (1509-1591) ese mismo año, en la que Teadkiel figura junto a la escena del sacrificio de Isaac; Piel, con la de Jacob luchando con el ángel; Mitatron, con la del paso del mar Rojo; Jophiel como preceptor de Sem; y Raziel, con la expulsión del Paraíso. Los nombres de estos ángeles se asemejan mucho a los que según los patriarcas hebreos presidian los planetas: Zapkiel a Saturno, Zadkiel a Júpiter, Camael a Marte, Rafael al Sol, Haniel a Venus, Miguel a Mercurio y Gabriel a la Luna ${ }^{14}$. Y con los que se asociaban con los propios patriarcas: Metattron con Moisés, Peliel con Jacob, Rafael con Isaac y Tobías, Raziel con Adán, Zadkiel con Abraham, Miguel con Salomón, Jophiel con Sem, Zaphkiel con Noé, Camael con Sansón, etc ${ }^{15}$.

\footnotetext{
${ }^{14}$ Agripa, 1982, 302.

${ }^{15}$ Brancasio de Caravinea, 1646, 456.
} 


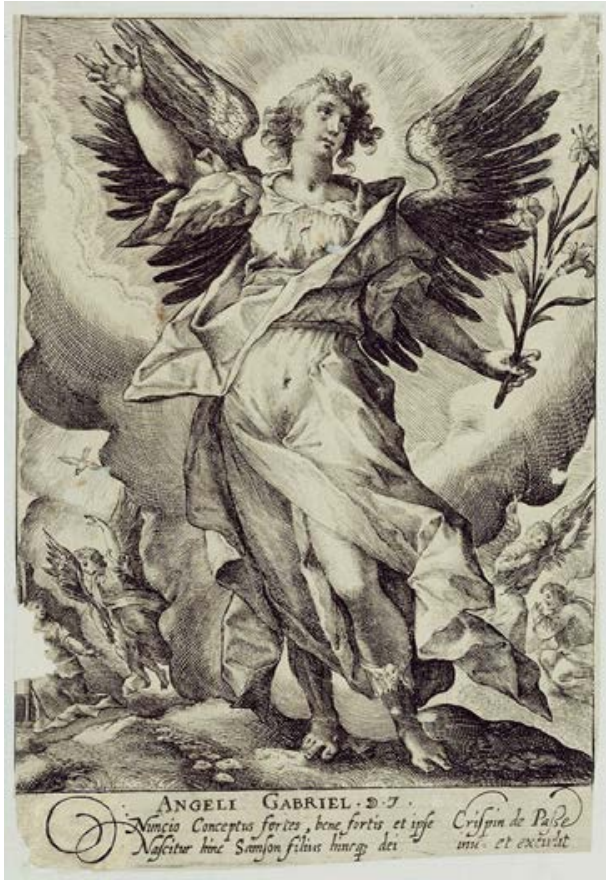

Fig. 12. Crispijn van de Passe (1564-1637). Angeli Gabriel. Grabado calcográfico. Ca. 1585 .

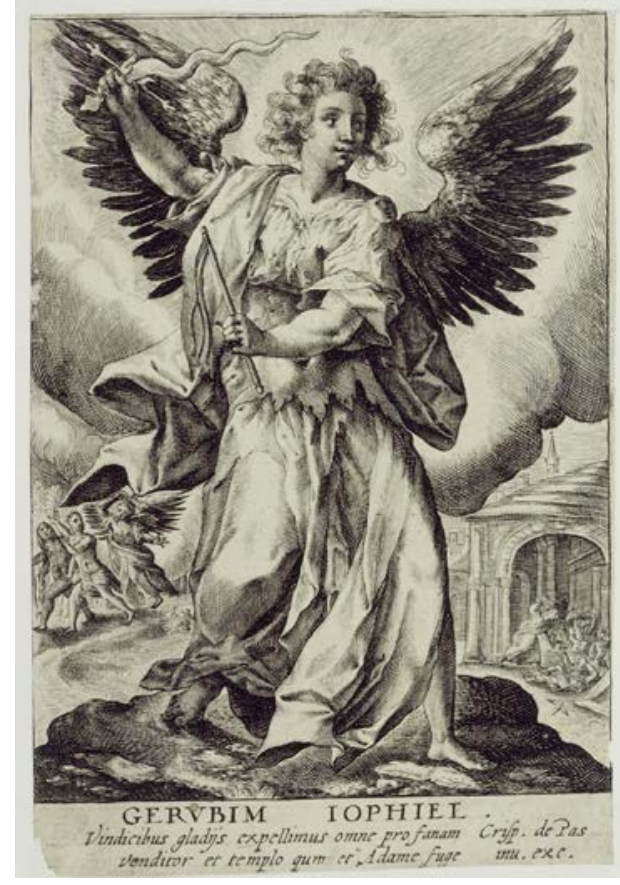

Fig. 13. Crispijn van de Passe (1564-1637). Gerubim Iophiel. Grabado calcográfico. Ca. 1585 .

Pero ya se han explicado las razones por las que no se puede intitular a los ángeles de la serie de Aguilar con esos nombres.(Fig. 12-14)

En la serie de Aguilar, los ángeles canónicos se reconocen fácilmente, pero desconocemos la identidad de los otros ángeles y el significado de la serie. Esos ángeles desconocidos figuran junto a escenas que representan la expulsión del Paraíso, el sacrificio de Isaac, el pecado de David que castigó Dios con la peste, la lucha de Jacob con el ángel, Daniel en el foso de los leones, el anuncio de la Navidad, y la liberación de San Pedro. La literatura angélica del Barroco repite frecuentemente, que los nombres propios de los ángeles solo Dios los conoce. Y que los nombres que nosotros les damos personifican los oficios y los beneficios angélicos. Los oficios de los ángeles son las misiones y ministerios que Dios les asigna:

«Porque el nombre de los Angeles, que son embiados, con despachos del Cielo, se varían conforme las legacias à que vienen, segun el beneficio, que hazen, es el nombre [...] Bien probado queda, que los nombres de los Angeles tienen su origen en las mercedes, en los dones, en los efectos, en las diligencias, en los beneficos, que nos hazen [...] No hablamos de los nombres de su naturaleza, que son muy secretos [...] sino de los que tienen, por sus oficios, y beneficios $[\ldots]$ para que los conozcamos y sirvamos» ${ }^{16}$.

Por su parte, los beneficios angélicos derivan de sus oficios, y son las mercedes materiales y espirituales que conceden los ángeles a sus devotos, que a su vez constituían el principal argumento que utilizaban los autores de los devocionarios para fomentar la devoción angélica, como puede verse en los dos devocionarios dedicados específicamente a los beneficios angélicos, Beneficios del Sto. Ángel de Nuestra Guarda de Martín de $\operatorname{Roa}^{17}$, y Beneficios del glorioso Angel de nuestra guarda de Blasco de Lanuza ${ }^{18}$. San Buenaventura había condensado estos beneficios en trece $«$ servicios» ${ }^{19}$. El

\footnotetext{
${ }^{16}$ Blasco de Lanuza, 1652, 314.

${ }^{17}$ Roa Francés, 1632. Hay otra edición en Lisboa de 1634.

${ }^{18}$ Blasco de Lanuza,, 1637.

${ }^{19}$ Blasco de Lanuza,, 1637.
} 


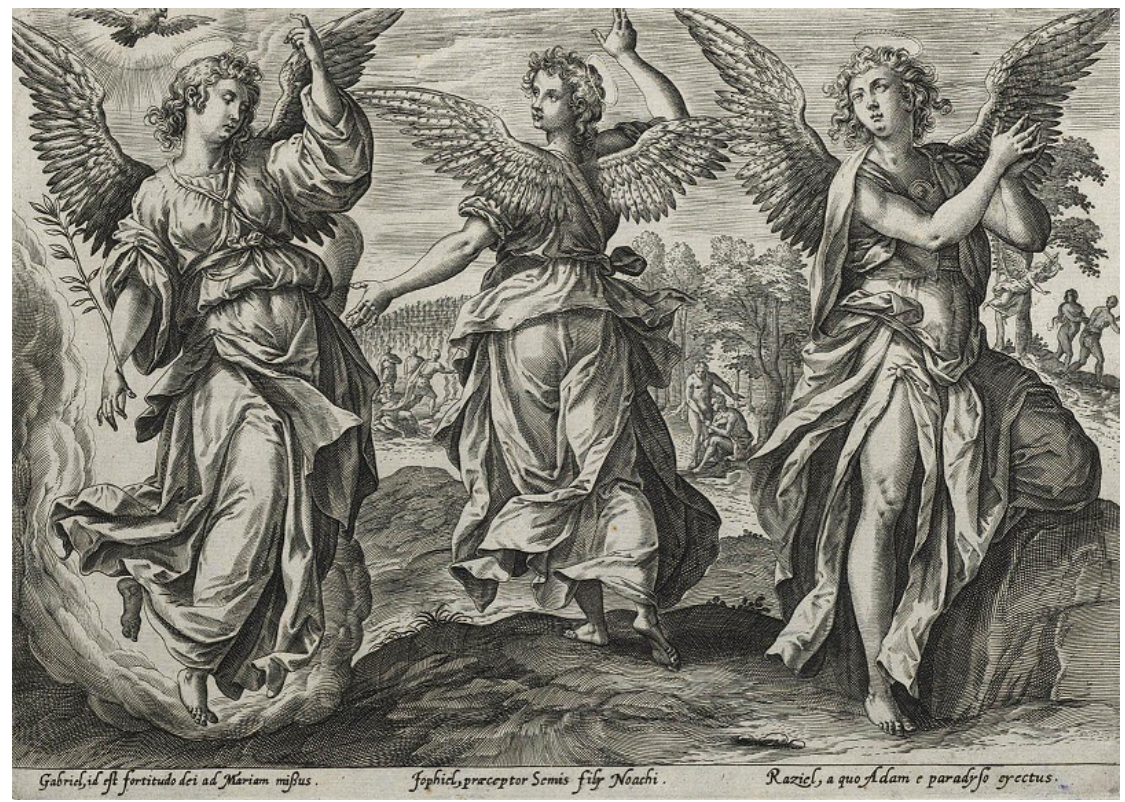

Fig. 14. Gerard de Jode (1509-1591). Gabriel. Jophiel. Raziel. Grabado calcográfico. Ca.1585.

primero, reprender a los pecadores; el segundo, fomentar la caridad; el tercero, combatir las tentaciones; el cuarto, fomentar las buenas obras; el quinto, custodiar a los viajeros; el sexto, revelar secretos celestiales; el séptimo, consolar a los afligidos; el octavo, ahuyentar a los demonios; el noveno, curar las enfermedades; el décimo, socorrer las tribulaciones; el undécimo, derrotar a los enemigos; el duodécimo, presentar a Dios las oraciones; y el decimotercio, «enseñar y dar doctrina». Y Blasco de Lanuza facilitó una relación de doce beneficios donde sintetizaba la doctrina de otros escritores sobre este asunto:

«Acostumbran los Sagrados Escritores, que tratan desta materia reducir los oficios de los Angeles en orden a los hombres; unos a catorce, otros a doze, otros a seys, ahora brevemente señalaremos doze, y despues dicurriremos por algunos mas principales [...] Primero [...] es incitar a lo bueno, y apartar de lo malo [...] Segundo [...] ofrecer a Dios nuestras oraciones [...] Tercero [...] quitar los peligros exteriores, espirituales, y corporales [...] Quarto [...] atar el poder del Demonio para que no tiente [...] Quinto [...] reprehender los pecados cometidos [...] Sexto [...] consuela [...] Septimo [...] guiarnos siempre, de noche, de dia, en qualquiera tiempo, en todo lugar [...] Octavo [...] mitigar las tentaciones [...] Nono [...] salir a nuestra defensa en forma visible $[\ldots]$ Decimo [...] sacarnos de gravissimos aprietos [...] Undecimo [...] exortar a todo genero de Virtudes [...] Duodecimo [...] castigar (como amoroso Maestro) para traer a enmienda ${ }^{20}$.

En los textos los beneficios van ilustrados con sus correspondientes exemplum; muchos de ellos eventos bíblicos protagonizados por los ángeles. Así, Blasco de Lanuza ponía como ejemplo de los castigos de los ángeles por los pecados de los hombres, los episodios de la burra de Balaam (Num. 22, 21-36) y el castigo a David con la peste en Jerusalén por realizar un censo (Sam. 24 y I Paralipómenos. 21). Como ejemplo de la ayuda que prestan los ángeles en «gravísimos aprietos», sus intervenciones en auxilio de Daniel, Isaac, Loth, Jonás, etc. De su asistencia en las adversidades, la que prestaron a Tobías y a Moisés cuando fue atacado por el faraón en el mar Rojo (Ex. 14, 19-20). Y de su apoyo para vencer las tentaciones, la lucha que sostuvo Jacob con el ángel en Panuel (Gén. 32,24-32). Y estos exemplum son precisamente los que acompañan a los ángeles en los grabados

\footnotetext{
${ }^{20}$ Blasco de Lanuza, 1637, 208-212.
} 


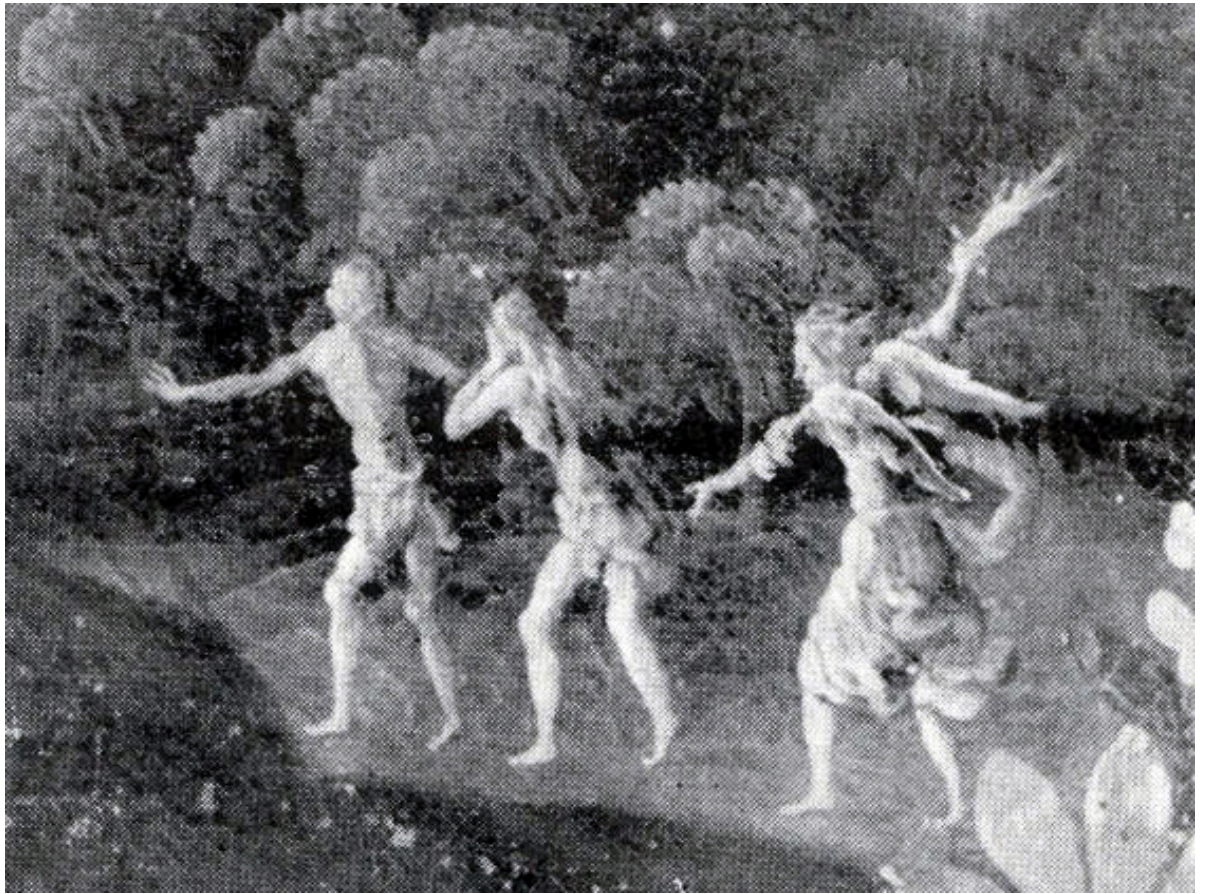

Fig. 14b. Expulsión del Paraíso. Escena representada en el cuadro titulado Ángel del Paraíso.

flamencos y en los cuadros de algunas series angélicas, lo que nos permite establecer paralelismos entre las imágenes y los textos. Entendemos que el significado de esta serie fue servir de alegoría de los beneficios angélicos, y que los ángeles deben intitularse Miguel, Gabriel bir Deus, Raphael Medisina Dei, Ángel de la Guarda, Ángel del Paraíso, Ángel de Isaac, Ángel de Jacob, Ángel de David, Ángel de Daniel, Angel de la Navidad, y Ángel de San Pedro. Se puede concluir por tanto que la serie del monasterio de San José y San Roque es una magnífica ilustración visual de los exemplum que ilustran los beneficios angélicos en los devocionarios barrocos; y que su presencia en el monasterio tenía una función devocional y catequética, ya que los ángeles y las escenas representadas fomentaban la devoción angélica entre las religiosas, y las servían de ejemplo de las mercedes angélicas.

Hay otras series donde los ángeles son semejantes en número y en iconografía a los de la serie de Aguilar, pero los cuadros tienen inscripciones que los identifican. Es el caso de las series del Hospital del Pozo Santo (Sevilla), iglesia del Divino Salvador de Sopó (Colombia), o monasterio de la Concepción de Lima. Es posible por tanto que los cuadros de San José y San Roque originariamente también las tuviesen, como sucede en los cuadros de Miguel, Gabriel bir Deus, y Rafael Medisina Dei. Esa fue al menos la costumbre en las series angélicas de los siglos XVII y XVIII, hasta que las representaciones y los nombres apócrifos de los ángeles fueron prohibidos por el clero ilustrado. El Edicto del Santo Oficio de 15 de Julio de 1747, ordenaba realizar numerosas expurgaciones, borrar imágenes y textos, y retirar del mercado algunos libros. Prohibía específicamente «qualquier Papel, Estampa, Estatua \&c. en que se hallen nombres de Angeles no reconocidos por la Iglesia», «toda Obra, Estampa, \&c. en que se dé culto á los Angeles Sealtiel, Uriel, Sehudiel, y Barachiel». Esta normativa provocó la desaparición de cuadros, la desmembración de series, y el borrado o repintado de los nombres de los ángeles. Sería conveniente por tanto inspeccionar los cuadros de esta serie con luces infrarrojas y ultravioleta, para comprobar si tienen textos ocultos con las identidades de los ángeles. Por otra parte, la reiteración de los atributos que portan los ángeles, y de las escenas que les acompañan, pone en evidencia que artistas y comitentes se regían por criterios y tradiciones similares en la selección de los ángeles que conformaban estas series.(Cuadro 1) 


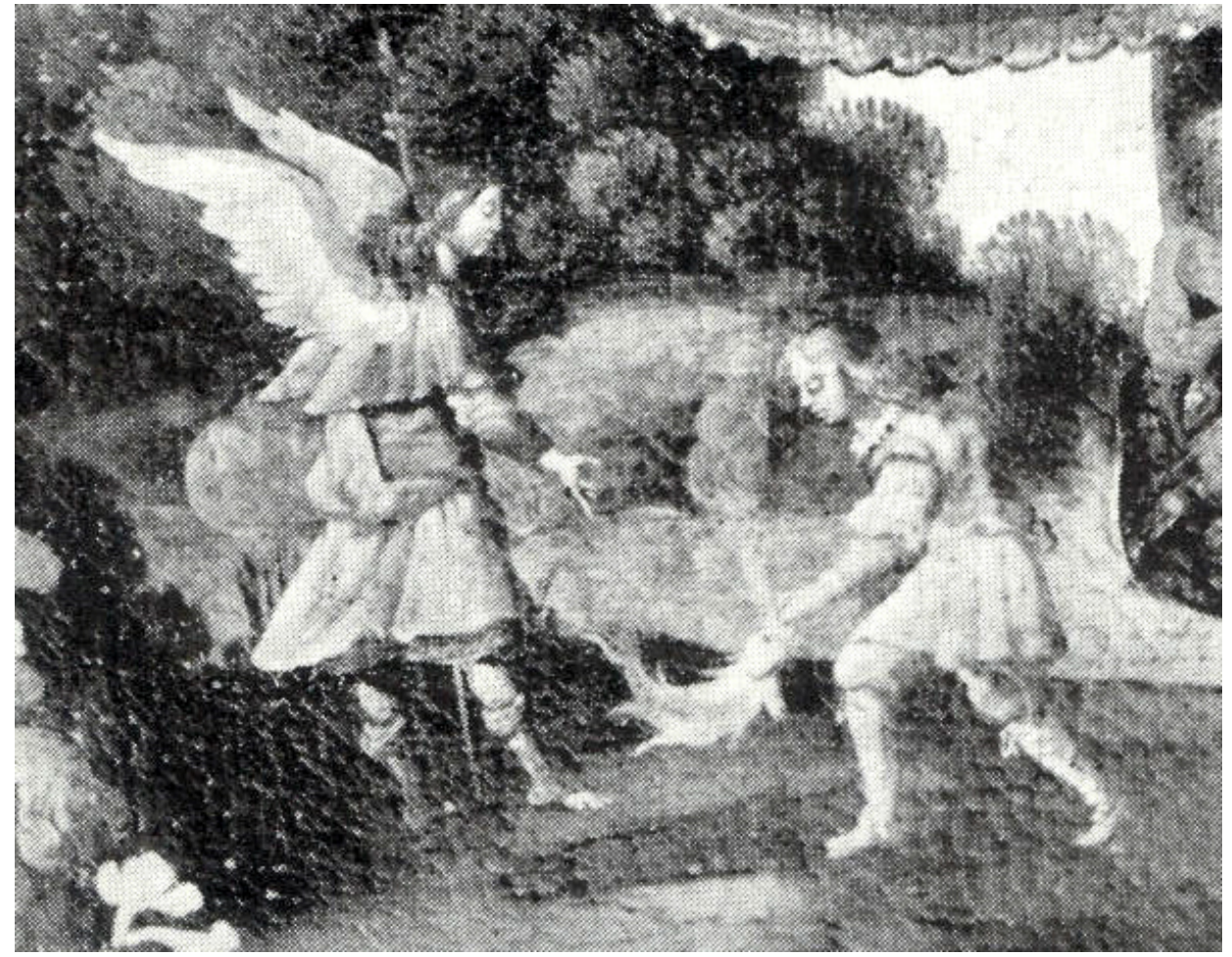

Fig. 14c. Rafael con Tobías. Escena representada en el cuadro titulado Raphael Medisina Dei.

En Aguilar de la Frontera existen otros conjuntos angélicos. Lara Arrebola informa de la presencia de otra serie en la parroquia de Ntra. Sra. del Soterrano ${ }^{21}$. Y en el mismo monasterio de San José y San Roque existen otros conjuntos angélicos. Tres son series de corales angélicas, datadas entre 1680 y 1710, e integradas perfectamente en la decoración mural del templo ${ }^{22}$. Dos están formadas por cuatro ángeles cantores y cuatro músicos que tocan la guitarra, el órgano, la flauta y el violonchelo, y van enmarcados con yeserías policromadas que forman parte de la decoración arquitectónica. Todos ellos son ángeles adolescentes de aspecto femenino, de largo

cabello rizado y vestidos con coloridas túnicas. Una tercera serie está formada por ocho rollizos angelotes semidesnudos, embutidos en marcos dorados y calados de estilo rococó, de abultados adornos, amplios copetes y hojas carnosas, que cuelgan unos debajo de otros entre los encuadramientos arquitectónicos. Y del mismo estilo y formato, se conserva una serie de ocho ángeles pasionarios, formada por un Ángel con corona de espinas, Ángel con columna de la flagelación, Ángel con flagelo, Ángel con martillo, Ángel con clavos, Ángel con lanza, Ángel con caña de hisopo y esponja, Ángel con cruz. (Fig. 15-18)

La existencia de tantas representaciones angélicas pone de manifiesto la gran devoción que esta localidad cordobesa profesó a los ángeles. A este respecto es particularmente significativa la petición que se realizó a principios del siglo XIX a la Sagrada Congregación de los Ritos ${ }^{23}$, para

\footnotetext{
${ }^{21}$ Lara Arrebola, F. 1980, 200.

22 Base de Datos de Bienes Muebles de Andalucía. Centro de Documentación. Códigos 1400200090048.004/7,1400200090048.012/15,1400200090049.005/12.

23 SACRA RITUUM CONGREGATIONE... Card. Zurla relatore, Panormitana, Corduben. et Oxomen. indulti reassumendi recitationem officii, et missae propr. in honorem septem angelorum ..., cum additione historica ad VI Lect..., sin minus pro civitate, et Diocesi Panormitana, et Sacellis Patronatus Oratoris in Oppidis Cabra, et Aguilar Diocesis Cordubensis, et in Oppido Seron Oxomensis Diocesis, istantibus ... Archiepiscopo Panormitano, et Petro Maria Heredia et Rio, Hispano. Roma, 1826. (ex Typographia Reverendae Camerae Apostolicae).
} 


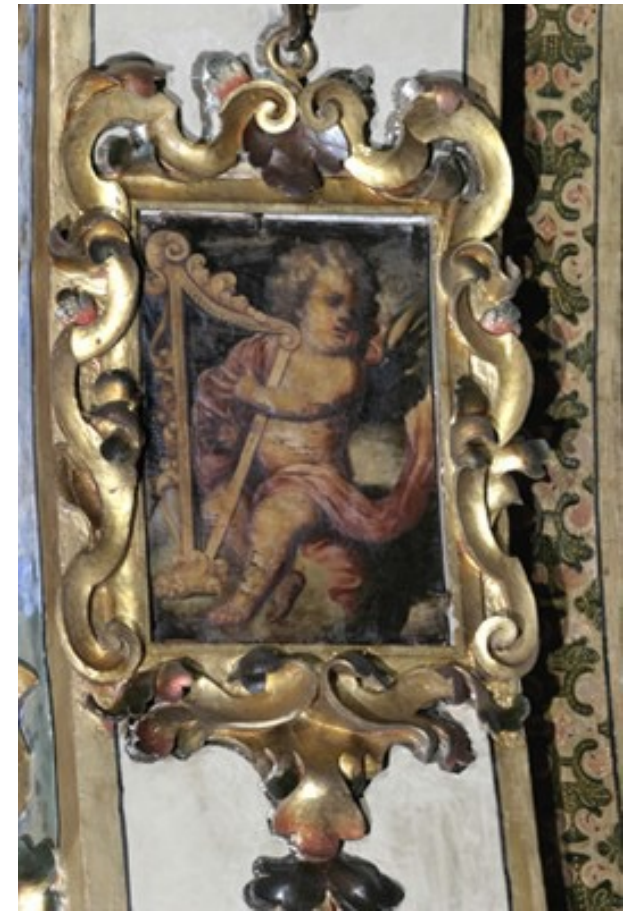

Fig. 15. Ángel con arpa. Monasterio de San José y San Roque de Aguilar de la Frontera (Córdoba). Escuela andaluza. Siglo XVIIXVIII.

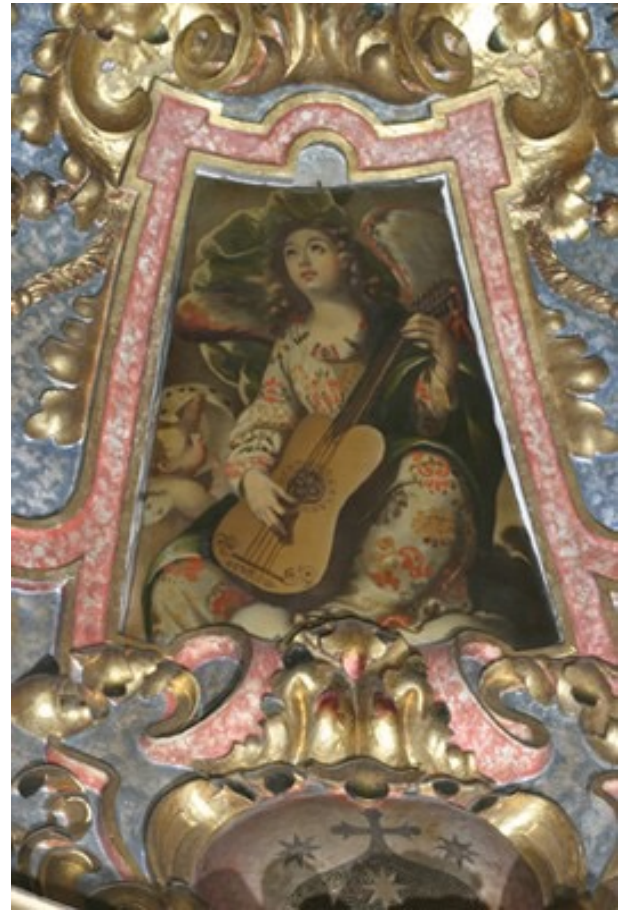

Fig. 16. Ángel con guitarra. Monasterio de San José y San Roque de Aguilar de la Frontera (Córdoba). Escuela andaluza. Siglo XVII-XVIII.

restaurar los Oficios y la Misa de los siete Príncipes de los Ángeles, que como hemos visto, prohibió el clero ilustrado a mediados del siglo XVIII. La solicitud la realizaba conjuntamente el cardenal Gravina, entonces arzobispo de Palermo, donde se descubrieron las famosas pinturas de los siete arcángeles en 1516, y D. Pedro María Heredia y Rio ${ }^{24}$, un militar español muy devoto de los ángeles ${ }^{25}$, quienes argumentaban en su petición que antiguamente se celebraban misas y oficios en honor de estos arcángeles en Palermo y en otros lugares de España, como en Serón de Nágima (Soria), Cabra y Aguilar de la Frontera (Córdoba). La solicitud fue apoyada posteriormente por numerosas instituciones y cargos eclesiásticos, pero la respuesta debió de ser negativa, ya que los Oficios no volvieron a celebrarse nunca.

\footnotetext{
${ }^{24}$ D. Pedro María Heredia y Rio fue un importante militar, político absolutista y escritor de temas religiosos. Estuvo algún tiempo en Nápoles, donde publicó De bello hispanico, poema (Nápoles, 1810).

${ }^{25}$ Heredia y Rio, 1823.
} 


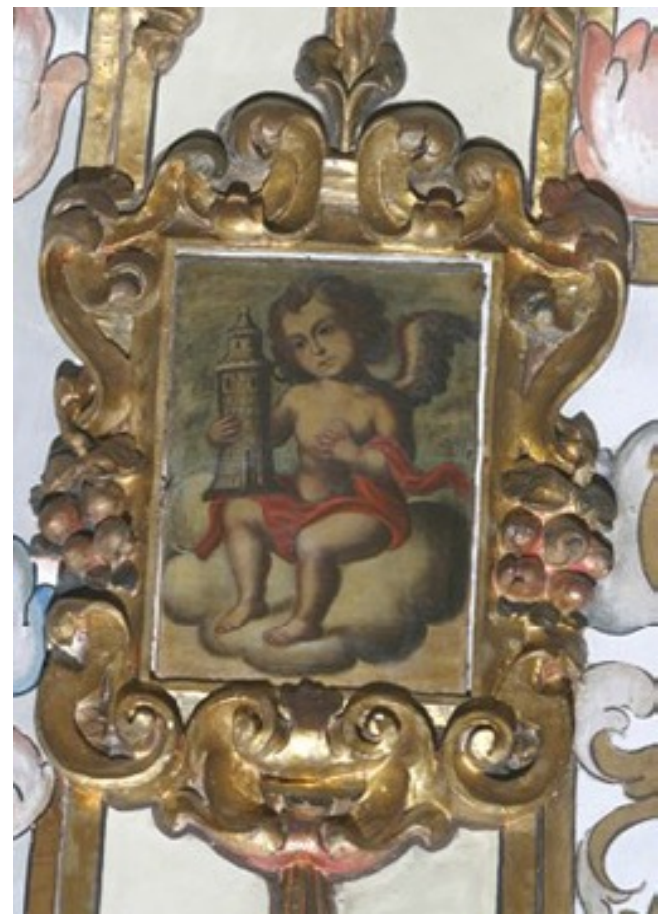

Fig. 17. Ángel con lanza. Monasterio de San José y San Roque de Aguilar de la Frontera (Córdoba). Escuela andaluza. Siglo XVII-XVIII.
Fig. 18. Ángel con torre. Monasterio de San José y San Roque de Aguilar de la Frontera (Córdoba). Escuela andaluza. Siglo XVII-XVIII.

Cuadro 1

ATRIBUTOS QUE PORTAN LOS ÁNGELES EN SERIES DE ÁNGELES APÓCRIFOS. No se incluyen los ángeles canónicos ni los Siete Príncipes.

\begin{tabular}{|c|c|c|c|c|}
\hline $\begin{array}{l}\text { Aguilar de la } \\
\text { Frontera (Córdoba) }\end{array}$ & Pozo Santo (Sevilla) & Tunja (Colombia) & $\begin{array}{l}\text { Concepción. } \\
\text { Lima (Perú) }\end{array}$ & $\begin{array}{l}\text { Calamarca } \\
\text { (Bolivia) }\end{array}$ \\
\hline $\begin{array}{l}\text { Rama de olivo. } \\
\text { Llave. } \\
\text { Espada en vaina. } \\
\text { Haz de llamas. } \\
\text { Columna partida. } \\
\text { Espada flamígera. } \\
\text { Haz de espigas. }\end{array}$ & $\begin{array}{l}\text { Corona y cetro. } \\
\text { Rama de olivo. } \\
\text { Llave. } \\
\text { Espada en vaina. } \\
\text { Haz de llamas. } \\
\text { Columna partida. } \\
\text { Palma y flores. }\end{array}$ & $\begin{array}{l}\text { Corona y palma. } \\
\text { Espada en vaina. } \\
\text { Haz de llamas. } \\
\text { Columna partida. } \\
\text { Espada flamígera }\end{array}$ & $\begin{array}{l}\text { Rama de olivo. } \\
\text { Espada en vaina. } \\
\text { Haz de llamas. } \\
\text { Espada } \\
\text { flamígera. }\end{array}$ & $\begin{array}{l}\text { Corona y cetro. } \\
\text { Rosas. } \\
\text { Llave. } \\
\text { Espada en vaina. } \\
\text { Haz de llamas. } \\
\text { Columna partida. } \\
\text { Espada flamígera. } \\
\text { Haz de espigas. }\end{array}$ \\
\hline
\end{tabular}




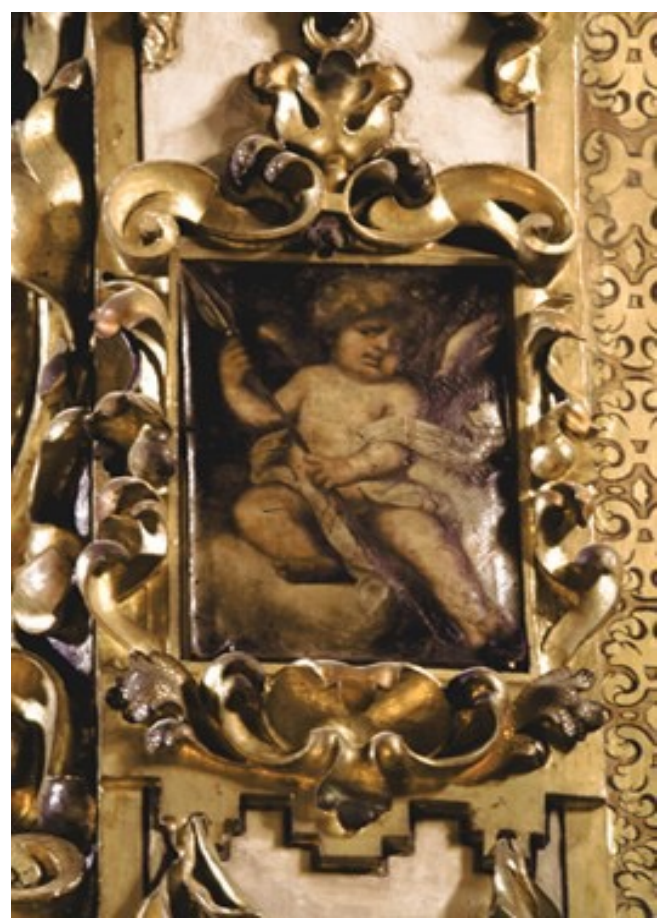


Bibliografía

Agripa, C.: La filosofía oculta: tratado de magia y ocultismo, Traducción de Héctor V. Morel. Buenos Aires: Editorial Kier. (1982).

Angulo Íñiguez, D./Pérez Sánchez, A. E.: Escuela madrileña del Segundo Tercio del siglo XVII. Madrid: CSIC. (1983).

Ávila Vivar, M.: Angelología Barroca. Las Series Angélicas. Ciudad Real: Universidad de Castilla-La Mancha. Tesis doctoral inédita. (2013).

Blasco de Lanuza, F.de (O.S.B.).: Beneficios del glorioso Angel de nuestra guarda.... Zaragoza: edición de Diego Dormer. (1637)

Blasco de Lanuza, F.de (O.S.B.).: Patrocinio de angeles y combate de demonios...: es vna ilustracion de los beneficios que hazen los Angeles de la Guarda à los hombres... / por... Fr. Francisco de Blasco Lanuza... de monges benitos claustrales...: Impresso en el Real Monasterio de San Iuan de la Peña: por Iuan Nogues. (1652).

Brancasio de Caravinea, C. (O.F.M.): De Angelis, Neapoli: ex Regia Typographia Egydii Longhi. (1646.

Delgado Martínez, N.: "Juan Antonio de Frías y Escalante (1633-1669)". En: Cuadernos de Arte e Iconografía, FUE., Tomo X, Núm. 20. Madrid, (2001), p. 316.

Fernández López, J.: Programas iconográficos de la pintura barroca sevillana del siglo XVII. Sevilla: Universidad de Sevilla. (1991).

Heredia y Rio, P.Ma: Colección de varias memorias y oraciones en honor de los Santos Ángeles, y en especial de sus siete príncipes para excitar à su devoción. Córdoba: imp. de D,L, de Ramos y Coria. (1823).

Lara Arrebola, F.: "Bernabé de Ayala y la serie de ángeles del monasterio de San José y San Roque de Aguilar de la Frontera". En: Boletín de la Real Academia de Córdoba de Ciencias, Bellas Letras y Nobles Artes, Año L, No 101, Córdoba, (1980), pp. 195-211.

Maluenda, L. De (O.F.M.).: Vergel de virginidad con el edificio spiritual de la caridad...Y otro tratado de los Mysterios de los angeles.../Burgos, en casa de Juan de Junta. (1539).

Roa Francés, M. de (S.I.): Beneficios del Sto. Ángel de Nuestra Guarda. En Córdoba por Salvador de Cea. (1632).

Torno y Monzó, E.: En las Descalzas Reales. Estudios Históricos, Iconográficos y artísticos. Madrid. (19151917).

Valdivieso, E.: "Ángeles sevillanos en Lima”. En: Buenavista de Indias, № 6, Sevilla, (1992), pp. 35-45. 